\title{
MISSION Possible, but Incomplete: Pairing Better Access with Better Transitions in Veteran Care
}

\author{
Joel M Bradley, MD ${ }^{1,23 *}$, Brian P Lucas, MD, MS ${ }^{1,2,4}$
}

'White River Junction VA Medical Center, White River Junction, Vermont; ${ }^{2}$ Geisel School of Medicine at Dartmouth, Hanover, New Hampshire; ${ }^{3}$ Children's Hospital at Dartmouth-Hitchcock, Lebanon, New Hampshire; ${ }^{4}$ The Dartmouth Institute for Health Policy \& Clinical Practice, Hanover, New Hampshire.

W hat childhood game better captures communication exchange than "telephone": as whispers pass from ear to ear, the original message degrades or transforms entirely. In complex healthcare systems, a more perilous version of "telephone" emerges, distinct from the well-worn metaphor: the signal never arrives at all. The primary care provider never even knew the patient was in the hospital; the discharge summary was never received; the patient cannot remember important details; and key medications are missing. In this edition of the Journal, Roman Ayele et al. ${ }^{1}$ used qualitative methods to explore this transitional black box between community hospitals and Veterans' Affairs (VA) primary care clinics, illuminating how signal fragmentation may render the increasing use of care services outside the VA system as inversely proportionate to quality.

To understand why, a small amount of historical context is necessary. The VA has increasingly focused on expanding healthcare options to its nine million veterans. On June 6, 2019, the VA Maintaining Internal Systems and Strengthening Integrated Outside Networks (MISSION) Act was passed to consolidate existing programs and lower barriers for Veterans to seek care in non-VA urgent care and subspecialty settings. ${ }^{2}$ Though this act is not specifically focused on access to community hospitals, patients seeking urgent and subspecialty care are likely to be increasingly hospitalized outside of the VA due to geographic factors affecting point-of-care decisions. Concurrent with this expansion of options is the planned replacement of the VA's legacy electronic health record, VistA. ${ }^{3}$ Both transformations indicate the need for the VA to be watchful and to intensify its focus on safe, effective exchanges of information.

Against this backdrop, Ayele et al. ${ }^{3}$ use stakeholder interviews with veterans and both non-VA and VA clinicians to identify the current lack of standardized practices for transitions of veteran care from community hospitals to VA primary care in Eastern Colorado. The themes most linked to care fragmentation included difficulty in identifying veterans and notifying VA primary care of hospital discharges, transferring medical

\footnotetext{
*Corresponding Author: Joel Bradley, MD; E-mail: Joel.M.Bradley@Hitchcock.
} org; Telephone: 802-295-9363 extension 5990; Twitter: @bradleyhashtag

Received: November 11, 2019; Revised: November 12, 2019;

Accepted: November 17, 2019

๑) 2020 Society of Hospital Medicine DOI 10.12788/jhm.3361 records, making follow-up appointments, and coordinating prescribing with VA pharmacies. Participants identified incomplete or delayed information exchanges that were further complicated by the inability to confirm transmission across systems. A patchwork of postacute care solutions failed to prevent wasteful, low-value transitional care, including unscheduled primary care walk-ins and ED visits for medication refills. Participants arrived at a simple common solution: develop a clinically trained "VA liaison" to work at the interface between VA primary care and non-VA community hospitals so as to provide a single point of contact to coordinate these transitions. In short, to have someone to pick up the phone.

The strengths of this qualitative study lie in its insights into the current gaps in care transitions through the eyes of key stakeholders. By engaging patients and providers in imagining system changes that are actionable in the near- (clinical VA liaisons) and longer-term (pharmacy and EHR integration), Ayele et al. have provided a helpful starting place in studying and improving the interface between VA and non-VA care. Stakeholders emphasized the importance of a clear access point so that outside providers can easily notify VA clinics, arrange follow-ups, and streamline physician prescribing to avoid dangerous and costly delays in care. ${ }^{4}$ Though similar issues have been illuminated in prior work on care fragmentation, ${ }^{4}$ perspective in context is a fundamental strength of qualitative research, and further highlights the urgency of this period in veteran care.

There is the old adage: "if you have seen one VA, you have seen one VA". This is arguably reflected in how each VA medical center is situated in a different regional and local healthcare delivery context, despite a common national infrastructure. The authors acknowledge limited generalizability but provide a framework for reproducing such work in regional VA systems. A national model for transitioning patients from regional community partners to VA primary care would require further testing, and to be a credible system-wide investment, would necessitate meaningful measurement across multiple sites. Given recent evidence of strong internal VA performance compared to the private sector, ${ }^{5}$ it is time for the VA to intensify focus on external care transitions. Given its history and continued commitment to funding innovation, ${ }^{6}$ the VA ought to be up to the task. Yet, as VA hospitalists, we know only too well that the system is increasingly under pressure to apply constrained resources inside and outside its own walls. Sending business elsewhere might not only fail at improving care but also weaken the fragile care delivery infrastructure. ${ }^{7}$ 
The idea that access and continuity may be in conflict raises an ethical question in modern practice and shared decision-making: how do we advise patients navigating complicated and imperfect health systems to understand the choices they are making and the risks they are taking when they spread care across systems? How are access and convenience weighed against the troubled movement of information across systems? How great is the risk if their care teams do not hear the same message? Knowing that increased fragmentation disproportionately affects the marginalized and vulnerable, especially those with complex chronic care needs, ${ }^{8}$ should we advise certain patients to stay in place within a single system?

As hospitalists, we are implied players in this dangerous version of the telephone game at a fascinating time in healthcare. Unlike when we advise patients on the risks and benefits of treatment, we have little evidence to guide our patients on when to stay put and when to leave to get care outside the system, inviting the risk of lost signals, garbled messages, and worst of all, frustrating, duplicative, unsafe care. As we strive for incremental improvements toward sweeping transformations in healthcare, we may for a few more years have to remind each other-and our students - of the incredible value of one more phone call: to make sure the intended message was received.
Disclosures: The authors have nothing to disclose.

Disclaimer: The contents of this publication do not represent the views of the U.S. Department of Veterans Affairs or the United States Government.

\section{References}

1. Ayele RA, Lawrence $E$, McCreight $M$, et al. Perspectives of clinicians, staff, and veterans in transitioning veterans from non-VA hospitals to primary care in a single VA healthcare system. J Hosp Med. 2020;15(X):XXX-XXX. https:// doi.org/10.12788/jhm.3320.

2. US Department of Veterans Affairs: VA Maintaining Internal Systems and Strengthening Integrated Outside Networks (MISSION) Act of 2018. https:// missionact.va.gov/ at https://www.congress.gov/115/bills/s2372/BILLS115s2372enr.pdf. Accessed October 31, 2019.

3. US Department of Veterans Affairs: VA EHR Modernization. ehrm.va.gov. Accessed October 31, 2019.

4. Thorpe JM, Thorpe CT, Schleiden L, et al. Association between dual use of Department of Veterans Affairs and Medicare Part D drug benefits and potentially unsafe prescribing. JAMA Intern Med. 2019;179(11):1584-1586. https://doi.org/10.1001/jamainternmed.2019.2788.

5. Weeks WB, West AN. Veterans Health Administration hospitals outperform non-Veterans health administration hospitals in most health care markets. Ann Intern Med. 2018;170(6):426-428. https://doi.org/10.7326/M18-1540.

6. US Department of Veterans Affairs: VA Innovation Center. https://www.innovation.va.gov/. Accessed October 31, 2019.

7. Shulkin, DL. Implications for veterans' Health Care: the danger becomes clearer [published online ahead of print July 22, 2019. JAMA Intern Med. 2019. https://doi.org/10.1001/jamainternmed.2019.2996.

8. Englander H, Michaels L, Chan B, Kansagara D. The care transitions innovation (C-Traln) for socioeconomically disadvantaged adults: results of a cluster randomized controlled trial. J Gen Intern Med. 2014;29(11):1460-1467. https://doi.org/10.1007/s11606-014-2903-0. 